\title{
Outcome of repeat dosing of sJIA patients with tocilizumab in one UK centre
} P Livermore*1, T Woodworth ${ }^{2}$ and $\mathrm{P} \mathrm{Woo}^{1}$

Address: ${ }^{1}$ Great Ormond Street Hospital, London, UK and ${ }^{2}$ Roche, Basel, Switzerland

* Corresponding author

from $15^{\text {th }}$ Paediatric Rheumatology European Society (PreS) Congress

London, UK. 14-17 September 2008

Published: 15 September 2008

Pediatric Rheumatology 2008, 6(SuppI I):P24 doi:I0.I I86/I546-0096-6-SI-P24

This abstract is available from: http://www.ped-rheum.com/content/6/SI/P24

(C) 2008 Livermore et al; licensee BioMed Central Ltd.

\section{Background}

Tocilizumab is effective in treating sJIA in a phase III Japanese study. Before the worldwide pivotal trial, 4 patients were admitted to the compassionate use programme available in 2006 at one UK centre.

\section{Methods}

Each patient was assessed clinically before dosing and laboratory markers recorded. The dose was $8 \mathrm{mg} / \mathrm{kg}$ fortnightly iv. All had steroids and methotrexate concurrently. The follow up period vary from 1 year to 18 months.

\section{Results}

In 3 patients CRP returned to normal after the first dose. $2 / 4$ patients were below $30 \mathrm{~kg}$ and only had transient lowering of CRP between doses. Active joint counts decreased partially in 2 and not in the 2 patients with body weight $<30 \mathrm{~kg}$ after 3 doses. These 2 patients were given $12 \mathrm{mg} /$ $\mathrm{kg}$ on the basis that pharmacokinetic modelling predicts underexposure to the drug if given at $8 \mathrm{mg} / \mathrm{kg}$, when the body weight is $<30 \mathrm{~kg}$. The higher dose led to improvements in clinical and laboratory markers. All were able to reduce steroid therapy. There were no significant side effects, apart from one with transient urticarial rash.

None are able to discontinue steroid therapy completely. One has significant growth retardation on $5 \mathrm{mg}$ prednisolone daily. One still had 22 active joints (decreased from 32) after one year with a normal CRP. She is now in remission after a bone marrow allograft.

\section{Conclusion}

Multiple dosing of tocilizumab has greatly improved the global disease activity of severe sJIA, but their arthritis requires concurrent steroids and methotrexate. PK/PD strategies to optimize dosing in sJIA may be indicated. 